\title{
Initial crack effect on the strength of oblique cross sections of reinforced concrete beams strengthened with carbon fiber
}

\author{
Alexandr Shilov ${ }^{1, *}$, Petr Polskoy ${ }^{1}$, Dmitriy Mailyan ${ }^{1}$, and Petr Shilov ${ }^{1}$ \\ ${ }^{1}$ Don State Technical University, Rostov-on-Don, Russia
}

\begin{abstract}
In the theory of reinforced concrete, the issue on strength of the oblique beam sections is more complicated than that on the standard sections, since it depends on many factors. The change of at least one of them leads to a significant change in the carrying capacity and in the structural damage pattern. This is due to the fact that at the operating level of the load, all conventional reinforced concrete structures work with cracks, which must be considered in the calculation. However, in the existing regulatory documents and public sources, this issue is not specified. This paper considers the effect of initial cracks on the strength of oblique cross sections of the reinforced concrete beams strengthened with carbon fiber. The experimental studies results obtained through the transverse force testing of forty-two prototypes made of heavy concrete of B30 design grade are presented. The test samples had initial oblique cracks of 0.6-0.9 mm width and were reinforced with three composite U stirrups from the fabric based on unidirectional carbon fibers in the shear span. Initial cracks in the beams were formed at three values of the shear span $1.5 \mathrm{~h}_{0}, 2 \mathrm{~h}_{0}$ and $2.5 \mathrm{~h}_{0}$. The test data show the impact of initial cracks on the efficiency of composite reinforcement of oblique cross sections of the prototypes at various values of shear spans.
\end{abstract}

\section{Introduction}

According to a long-range research program, the Reinforced Concrete and Masonry Structures Department, DSTU, is conducting large-scale studies on the behavior of reinforced concrete $(\mathrm{RC})$ structures, with internal and external composite reinforcement. Since 2012, comprehensive studies of the RC structures have been carried out using round GRP and CFRP bars. The strength of normal to longitudinal axis of the section structures of flexible concrete elements, with normal and excess cross-sectional area of composite materials, is studied. Experimental studies of the compressed RC elements reinforced with composite materials with various eccentricities of load application are completed [1-6]. Currently, the strength of oblique cross sections of RC beams with initial diagonal cracks strengthened through the external composite transverse reinforcement is investigated.

\footnotetext{
${ }^{*}$ Corresponding author:ale381420082008@yandex.ru
} 
Studies on bending RC elements reinforced with composite materials are conducted in foreign countries as well. Despite the availability of a sufficiently large amount of information on the behavior of RC structures reinforced with composite materials in foreign literature and scientific publications, many questions are still not studied and are of great interest to modern researchers. For example, the interaction of steel internal and external composite reinforcement, as well as the stress and strain level of composite stirrups in the pre-failure stage of operation, is investigated with the help of analytical models [7]. Concurrently, the relationship between the carrying capacity of oblique cross sections and the rupture load for oblique sections reinforced with composite stirrups, in the absence of anchor devices for composite stirrups, is studied [8]. In a number of foreign countries, null data on some issues that are important for the calculation and design of the reinforcement elements in the regulatory documents on the RC structures strengthened with composite materials is a challenge. For example, now, the effect of the shear span on the behavior of oblique cross sections reinforced with composite U stirrups [9] is being actively studied. Software design systems based on neural networks [10] are developed; and the computational tool for the RC structures strengthened with composite materials presented in existing regulatory documents is updated [11-15]. The release of the Code of Rules SP 164.1325800.2014, 2014, dedicated to the strengthening of reinforced concrete structures with composite materials, gave an additional incentive to conduct scientific research in this field, but did not solve all the problems. These include: the degree of influence of existing oblique cracks of various projections and crack width on the strength of reinforced structures; the impact of the shear span when testing the reinforced element; design issues, etc.

Regulations of other countries do not give a specific answer to these questions either. The research needs to investigate the issues are justified through such factors as the reconstruction of buildings, at which the rearrangement and replacement of industrial production facilities is frequently carried out. As a result, the pattern of applying load on building structures is changed. Crucially, many building structures work with cracks, the width of which often exceeds the admissible values.

\section{Materials and Methods}

This paper considers the impact of existing oblique cracks of more than $0.4 \mathrm{~mm}$ width on the bearing capacity of the beams strengthened through the external composite reinforcement and tested at three different values of the shear spans: $a=1.5 \mathrm{~h}_{0} ; 2 \mathrm{~h}_{0}$ and $2.5 \mathrm{~h}_{0}$.

For the experiment, beams $2.0 \mathrm{~m}$ in length and with the cross section of $125 \times 250 \mathrm{~mm}$ were manufactured. The prototypes had the same longitudinal and transverse reinforcement. Steel working reinforcement was from $2 \varnothing 18$ A500, and the mounting one from $2 \varnothing 6 \mathrm{~V} 500$. The transverse reinforcement was represented by tied stirrups of Ø3B500 installed at a pitch of $150 \mathrm{~mm}$ (Fig. 1).

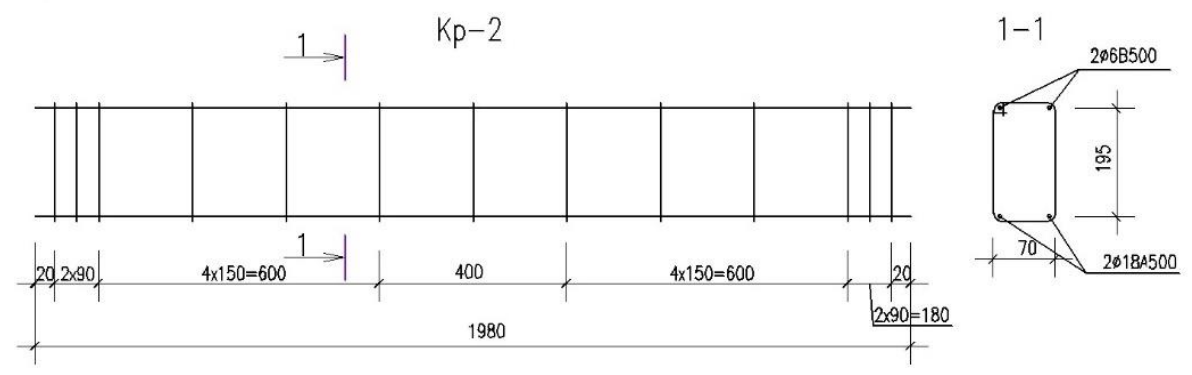


Fig. 1. Frameworks for prototypes

A total of 21 beams were tested or 42 prototypes, 6 of which were reference samples. The remaining 18 beams had initial cracks formed during the above shear spans in one of the supporting areas only. The second supporting area was strengthened by a steel casing for the testing time. The reinforcement and trial patterns of the test beams are shown in Fig. 2 and Fig. 3 respectively.

After the formation of oblique cracks, all the test beams were reinforced with threesided U-shaped MBrace Fib CF 230/4900/300 carbon fiber stirrups $0.166 \mathrm{~mm}$ in thickness. The strength of one layer determined through testing is equal to $3200 \mathrm{MPa}$.

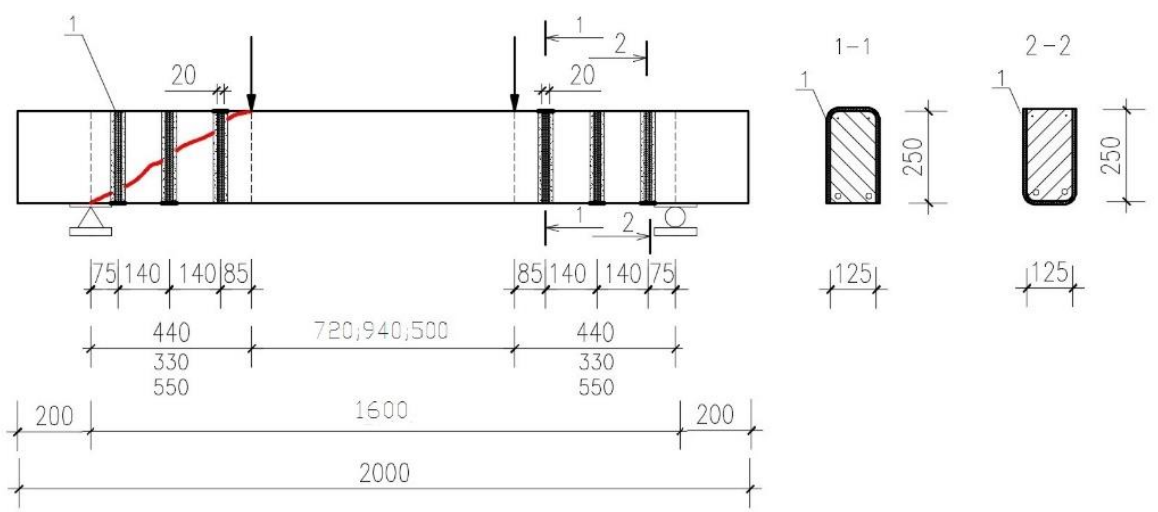

Fig. 2. Pattern of reinforcement of test beams with triangular $U$ stirrups

The reinforced test beams, as with the crack formation, were checked at three different shear spans: $1.5 \mathrm{~h}_{0}, 2 \mathrm{~h}_{0}$ and $2.5 \mathrm{~h}_{0}$.

Each test beam was checked twice. All prototypes were tested by the incrementally increasing load through the scheme of a single-span hinged beam loaded with two concentrated forces. Before testing the reinforced samples, one of the supporting areas was also strengthened with a steel casing according to the scheme in Fig. 3. After the destruction of one of the supporting areas, it was also reinforced with a steel casing, after which the beam was retested until the second shear span was destroyed.

This testing technique doubles the number of samples and, using the direct comparison of experimental data, obtains reliable results at exactly the same concrete strength values, cross-sections of steel longitudinal and transverse reinforcement, and at all other factors being equal.

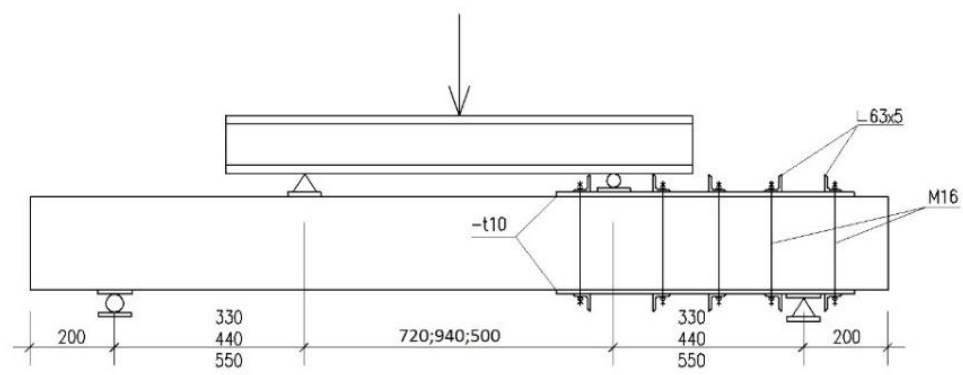

Fig. 2. Trial pattern of test beams 


\section{Research Results}

The strength test results and data of the initial oblique cracks impact on the composite reinforcement efficiency are shown in the graphs (Fig. 4-6) and in Table 1. They demonstrate that the transverse composite reinforcement efficiency depends on all variable factors, namely: presence or absence of the initial oblique cracks; shear span at which the initial cracks were formed and the reinforced specimens were tested.

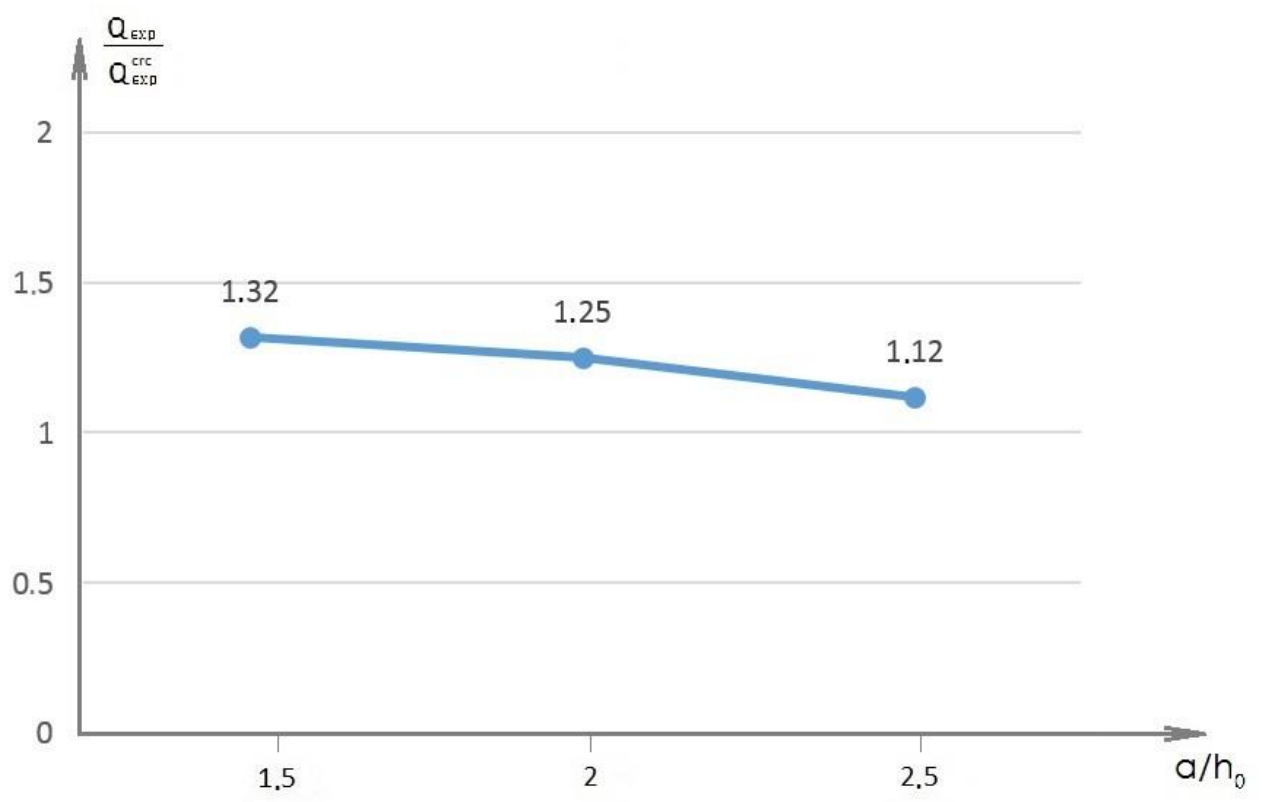

Fig. 4. Impact of initial cracks formed at shear span $\left(\mathrm{a}=1.5 \mathrm{~h}_{0}\right)$ on strength of reinforced cross-sections at different shear spans 


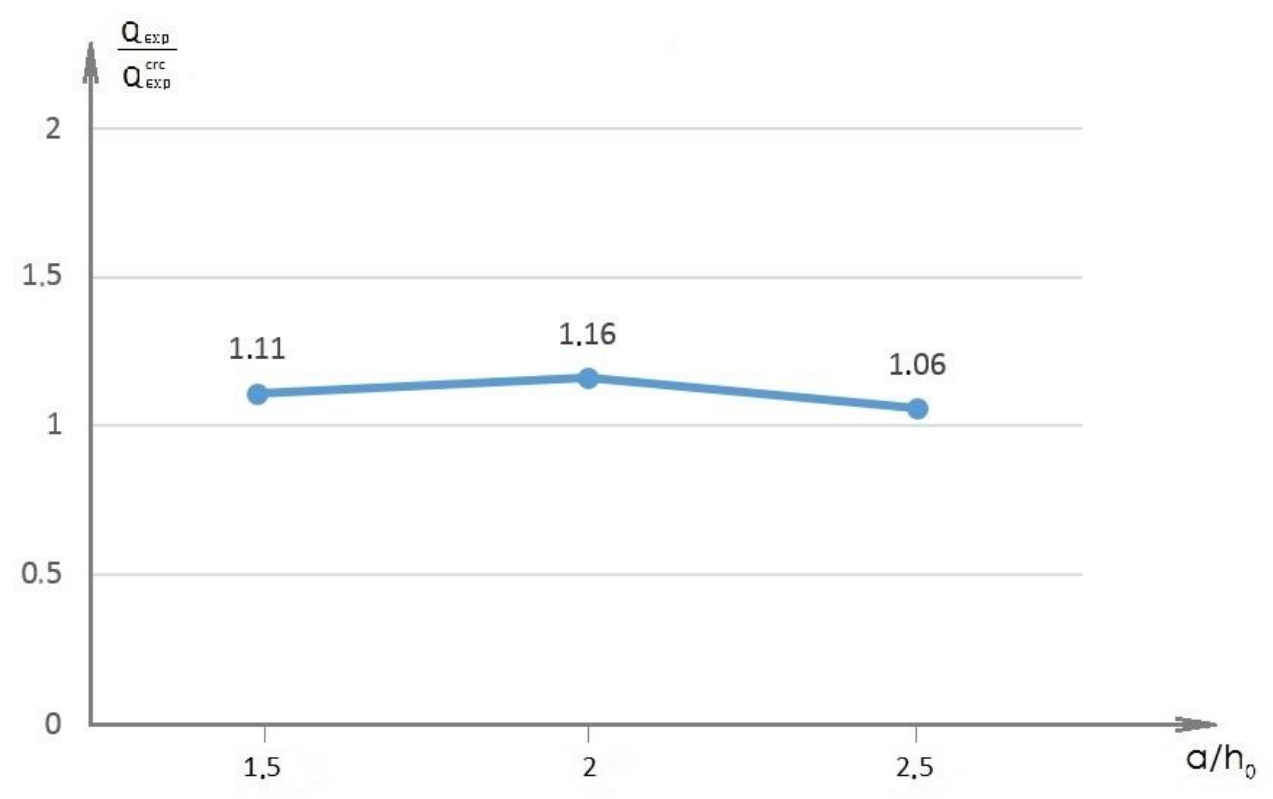

Fig. 5. Impact of initial cracks formed at shear $\operatorname{span}\left(\mathrm{a}=2 \mathrm{~h}_{0}\right)$ on strength of reinforced cross-sections at different shear spans

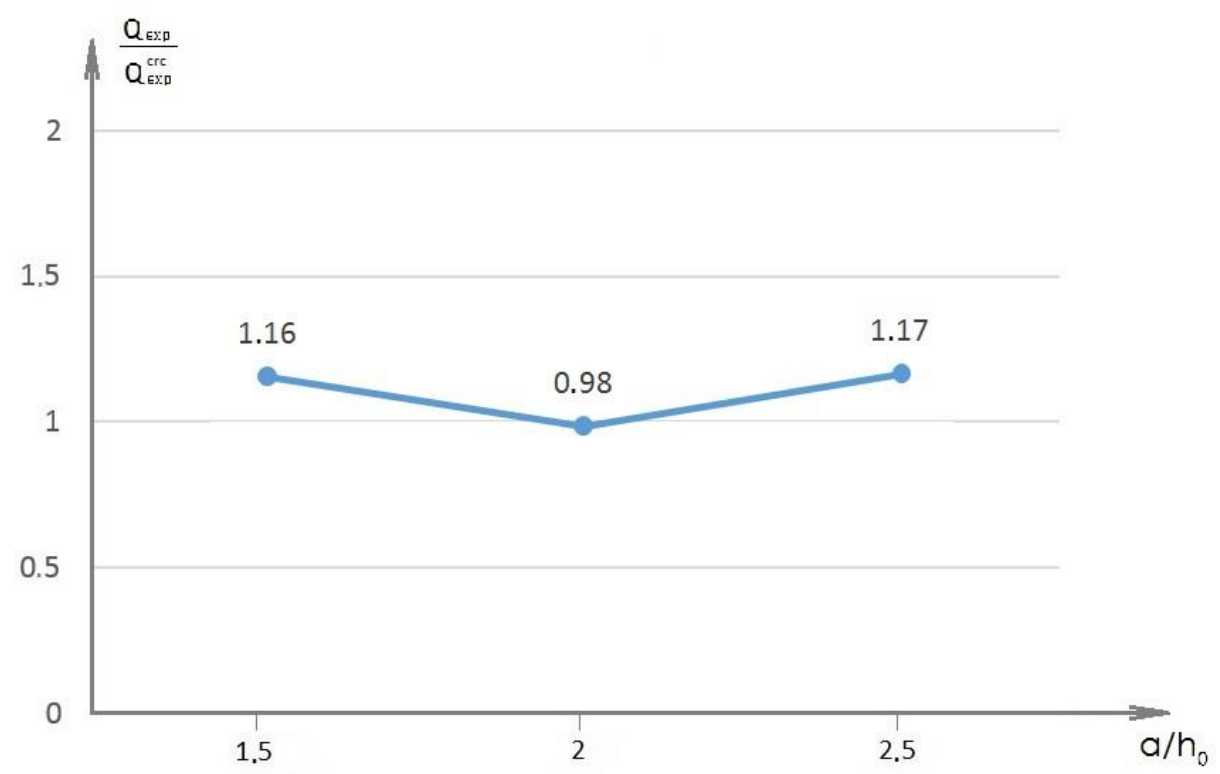

Fig. 6. Impact of initial cracks formed at shear span $\left(a=2.5 h_{0}\right)$ on strength of reinforced cross-sections at different shear spans 
Table 1. Impact of initial oblique cracks on strength of oblique cross-sections reinforced with carbon fiber

\begin{tabular}{|c|c|c|c|}
\hline $\begin{array}{c}\text { Shear span for } \\
\text { initial cracks }\end{array}$ & \multicolumn{3}{|c|}{$\begin{array}{c}\text { Ratio of oblique sections strength } \\
\left(Q_{\exp } / Q_{\text {exp }}^{c r c}\right) \text { tested through shear span: }\end{array}$} \\
\cline { 2 - 4 } & $\mathbf{1 . 5 \mathbf { h } _ { 0 }}$ & $\mathbf{2} \mathbf{h}_{0}$ & $\mathbf{2 . 5 \mathbf { h } _ { 0 }}$ \\
\hline $1.5 \mathrm{~h}_{0}$ & 1.32 & 1.25 & 1.12 \\
\hline $2 \mathrm{~h}_{0}$ & 1.11 & 1.16 & 1.06 \\
\hline $2.5 \mathrm{~h}_{0}$ & 1,16 & 0.98 & 1.17 \\
\hline
\end{tabular}

Note: the symbols ( $\left.Q_{\text {exp }}, Q_{\text {exp }}^{c r c}\right)$ indicate the shear force limit value perceived by the oblique cross section without the initial crack and with it, respectively.

\section{Conclusions}

The data analysis has shown the following:

1. Within each series, the decrease in the load-bearing capacity of the prototype with the initial crack, compared to a similar one without an initial crack, attained a maximum when the shear span at which the crack was formed coincided with the shear span when the reinforced sample was tested.

2. The most unfavorable combination of factors for the structures strengthened with carbon fiber on the supporting areas is the presence of cracks formed at $a=1.5 \mathrm{~h}_{0}$ and the load application after reinforcement of the structure with a similar shear span.

3 . The cracks formed at the shear span equal to $2.5 \mathrm{~h}_{0}$ exert the least impact on the carrying capacity of the oblique cross sections. However, the efficiency of composite reinforcement at the given shear span appeared simultaneously lower than the result of test samples at $a=$ $1.5 \mathrm{~h}_{0}$ and $a=2 \mathrm{~h}_{0}$. Therefore, the excess of $Q_{\exp }^{\text {crc }}$ value over $Q_{\exp }$ value should be considered in terms of the experimental scatter only.

4. The reinforced prototypes tested at the shear span of $a=2 \mathrm{~h}_{0}$, regardless of the shear span size, at which the initial cracks were obtained, appeared the most efficient in terms of the resistance to external influence.

The experiments performed show that, when designing reinforcing composite elements for oblique cross sections of the strengthened concrete components, account must be taken of the most disadvantageous options for the formation of oblique cracks. Solid closed or solid U-shaped stirrups should be considered the most reliable option for the reinforcement when applying a load with the shear span of $1.5 \mathrm{~h}_{0}$.

For the foregoing reasons, such factors as the presence of initial cracks, their projections, and the shear span size, markedly affect the strength of reinforced structures, which, at the moment, is not considered in the calculation as far as is necessary.

\section{References}

1. V. Muradyan, D. Mailyan, A Lyapin, V. Chubarov, IOP Conference Series: Earth and Environmental Science 19. "Energy Management of Municipal Transportation Facilities and Transport, EMMFT 2017”, p. 012032 (2017) 
2. D. Mailyan, V. Aksenov, N. Aksenov, Advances in Intelligent Systems and Computing, 692, 536-543 (2018)

3. P. Polskoy, D. Mailyan, S. Georgiev, V. Muradyan, E3S Web of Conferences (2018) https://doi.org/10.1051/e3sconf/20183302060

4. P. P. Polskoy, D. R. Mailyan, D. A. Dedukh, S. V. Georgiev, Global Journal of Pure and Applied Mathematics, 2, 1767-1786 (2016)

5. P. P. Polskoy, S. V. Georgiev, V. A. Muradyan, A. A. Shilov, MATEC Web of Conferences 196, 02026 (2018)

6. P. P. Polskoy, ISSN 1662-9752, 931, p. 315-320. URL: scientific.net/VSF.931.315

7. N. Spinella, Modeling of Shear Behavior of Reinforced Concrete Beams Strengthened with FRP, Composite Structures (2019) doi:https://doi.org/10.1016/j.compstruct.2019.02.073

8. M. S. Alam, A. Hussein, Construction and Building Materials, 154, 819-828 (2017)

9. W. Li, C.K.Y. Leung, Effect of shear span-depth on mechanical performance of RC beams strengthened in shear with U-wrapping FRP strips, Composite Structures (2017) doi: dx.doi.org/10.1016/j.compstruct.2017.06.059

10. H. Naderpour, O. Poursaeidi, M. Ahmadi, Shear Resistance Prediction of Concrete Beams Reinforced by FRP Bars Using Artificial Neural Networks, Measurement (2018) doi: https://doi.org/10.1016/j.measurement.2018.05.051

11. Kourosh Nasrollahzadeh, Reza Aghamohammadi, Engineering Structures, 176, 785-800 (2018)

12. X. Zou, P. Feng, J. Wang, Y. Wu, Y. Feng, FRP stay-in-place form and shear key connection for FRP-concrete hybrid beams/decks, Composite Structures (2018) doi: https://doi.org/10.1016/j.compstruct.2018.03.011

13. M. A. Colalillo, S. A. Sheikh, Behavior of shear-critical reinforced concrete beams strengthened with fiber-reinforced polymer - experimentation. ACI Struct J, 111(6), 1373-1384 (2014)

14. Guide for the design and construction of externally bonded FRP systems for strengthening concrete structures, ACI 440.2R-08. American Concrete Institute, p. 76 (2008)

15. Eurocode 2: Design of concrete structures - Part 1-1, General rules and rules for buildings, p. 229 (2004) 